\title{
Multi-Scale Rheo-Mechanical Study of SMA Mixtures Containing Fine Crumb Rubber in a New Dry-Hybrid Technology
}

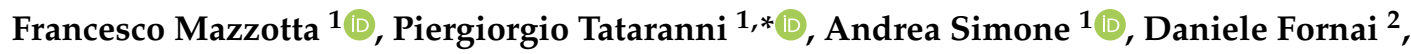 \\ Gordon Airey $^{3}{ }^{(B)}$ and Cesare Sangiorgi ${ }^{1}{ }^{1(D)}$ \\ 1 DICAM, University of Bologna, Viale Risorgimento 2, 40136 Bologna, Italy; \\ francesco.mazzotta2@unibo.it (F.M.); andrea.simone@unibo.it (A.S.); cesare.sangiorgi4@unibo.it (C.S.) \\ 2 Ecopneus Scpa, Via Messina, 38-Torre B, 20154 Milano, Italy; d.fornai@ecopneus.it \\ 3 Faculty of Engineering, The University of Nottingham, University Park, Nottingham NG72RD, UK; \\ gordon.airey@nottingham.ac.uk \\ * Correspondence: piergiorg.tataranni2@unibo.it
}

Received: 6 May 2020; Accepted: 2 June 2020; Published: 3 June 2020

\begin{abstract}
Aiming to study the rheo-mechanical effects of fine crumb rubber into gap graded stone mastic asphalt (SMA) mixtures, a multi-scale experimental approach was adopted. Therefore, in the perspective of the reuse of end of life tires' in asphalt layers, the adopted new dry-hybrid technology effects have been investigated from the mastic, mortar and mixture points of view. The new rubberized asphalt production technology allows the use of rubber powder as filler, the rubber amount optimization being validated through multi-scale performance tests. Mastics and mortars' complex modulus measured with dynamic shear and torsional tests were related to the mixture stiffness modulus recorded in direct tension-compression mode. The rheological properties of mastic are strictly influenced by the rubber presence, and consequently the asphalt mixtures stiffness and thermo-sensitivity are connected to the mastic and mortar rheo-mechanical behavior. Results are consistent through the adopted approach and reveal that with the new dry-hybrid technology, overcoming the wet and dry limits, it seems to be possible obtaining more durable and eco-friendly bituminous pavement layers.
\end{abstract}

Keywords: fine crumb rubber; dry-hybrid technology; mastic and mortar; dynamic shear rheometer; recycling

\section{Introduction}

The first applications of waste rubber form end of Life tires (ELT) for the production of bituminous mixtures date back to the 1960s'. Since then, this field of research has gained popularity and the production technologies have gradually tried to couple both material performances and sustainability [1].

The wet method was the first production process developed by Charles McDonald in the United States. The addition of recycled rubber to a bituminous mixture resulted in the so-called asphalt rubber (AR), characterized by great elasticity and viscosity at high temperatures [2-4]. However, AR binders showed issues related to production stability and storage properties [5]. Specific bitumen modification plants have been developed to solve these problems, allowing the continuous motion of the rubber particles, spreading them uniformly in the binder volume [6]. However, the environmental impact of this technology is still consistent, considering the high temperatures needed during the in-plant production and paving operations. As stated by Fornai et al. [7], despite its well-known advantages, AR technology has never been applied extensively. Furthermore, as highlighted in the 
last few international asphalt rubber conferences, a well-defined track in the use of this rubberized bituminous mixture has still to come.

Thus, despite that AR technology was developed around 60 years ago, it is still not considered as a common practice in many countries. In Europe, apart from Spain and Portugal, AR was mainly adopted for research purpose. Experimental applications highlighted the advantages of the material. However, the downsides related to the high binder viscosity [8] as well as the need of special plants and specific productions operations prevented its development on a large scale.

For these reasons, the potential addition of recycled rubber for the production of asphalt concretes (ACs) has been continuously investigated in the last 30 years. Most of the issues related to AR were overcome with the introduction of the dry technology $[9,10]$, in which the crumb rubber $(\mathrm{CR})$ is added to the bituminous mixture in substitution of the fine part of the aggregates [11,12]. However, this requires a specific mix design in order to have benefits from the addition of rubber within an AC [13]. In recent years, some novel technologies have been developed in Italy and Spain in order to merge the benefits given by polymer modified binders (PmBs) and the properties of a rubberized asphalt [14,15]. In Italy, the new technology is called "dry-hybrid" and it is based on the addition of CR as partial substitution of the traditional limestone filler. Furthermore, this technology provides for the use of modified bitumen with SBS (styrene-butadiene-styrene) polymer and paraffinic wax. Thus, it is possible to reduce the production and working temperatures. As showed in previous studies $[7,8]$ the final aim is to add the recycled $\mathrm{CR}$, without a significant modification in the asphalt plant and in the production process of a common modified AC. The proposed novel technology has been used for the production of a stone mastic asphalt (SMA) considering its high stones content. This creates a gap-graded skeleton-like stone structure that can be filled with a high viscosity bituminous mastic of $\mathrm{PmB}$ bitumen and filler [16,17].

The positive outcomes of the dry hybrid technology have been shown in several recent studies.

Researchers have highlighted the benefits given by this production method with experimental applications on bituminous mastics, mortars and ACs. Vignali et al. [18] analyzed bituminous mastics containing both filler and fine CR through rheological tests and discrete element methods (DEM) modelling. Results showed that the combination of fine CR and limestone filler enhances the mastic stiffness at high temperatures, increasing its rutting resistance. Frequency sweep tests and multiple stress creep recovery test results indicate that the addition of fine $\mathrm{CR}$ improves the complex modulus of the mastic if compared to the one produced with only limestone filler. At the same time, the rubber lowers the mastic thermo-sensitivity, limiting its tendency to glassy modulus at low temperatures and increasing the mastic resistance to thermal cracking. From an environmental point-of-view, recent applications on trial fields have demonstrated that the dry-hybrid technology makes the workers less susceptible to potentially harmful substances produced during the mixing, laying and compaction processes. Still, in terms of performance, the obtained pavement surface texture ensures adequate skid resistance and has acoustic properties allowing the reduction of traffic noise emissions [8].

However, the addition of $C R$ as a partial filler replacement requires further analysis on the behavior of the mastic inside the mixture, with particular reference to the fine aggregates fraction. It is also evident that the SMA mixtures being particularly rich in bituminous mastics, its interaction with aggregates has a significant influence on the properties of the final material. Therefore, a multi-scale approach is needed in order to fully understand the rheo-mechanical behavior of this novel bituminous mixture and characterize the dry-hybrid technology in a range of materials.

In this context, the expansion of the investigation field, from mastic to fine aggregate matrix (FAM) with standardized composition, has the primary purpose of evaluating the role of fine CR at different scales in order to optimize the AC design. Underwood and Kim [19] considered crucial the FAM behavior, because it is a single length scale smaller than the AC and it is therefore closer in the characteristic size of the damage that occurs within a bituminous mixture. The FAM, in fact, consists of bitumen, filler-sized particles, fine aggregate particles and air. This agglomerate forms the interstitial spaces between the coarse aggregates in a common bituminous mixture. Tests and studies on FAMs have been used to deeply analyze the fatigue damage, moisture sensitivity and healing in ACs. Indeed, 
all the aforementioned phenomena occur largely between the coarsest aggregate particles. Thus, FAM should provide direct indications of how it affects the ACs [20]. However, a specific analysis of FAM is not enough to have a complete picture of the behavior of ACs. As previously stated, in order to understand completely the macro-mechanical response of a heterogeneous composite, its mechanical response at different length scales must be analyzed. In the light of the above, the main objective of this article is a complete analysis of a SMA mixture containing fine CR according to a dry-hybrid technology, carried out with a multiscale approach, in order to find rheo-mechanical parameters able to optimize its mix design.

For a better explanation of the multiscale approach, the following scales of analysis were investigated:

- Matrix: coarse, fine aggregates and filler with bitumen.

- Mortar: fine aggregates and filler with bitumen.

- Mastic: filler with bitumen.

\section{Materials}

\subsection{SMA Mix Design}

The mix design for the SMA was done according to the District of Bologna technical specifications. The experimental mixture (labelled SMACR) was designed with a fine CR $(0-0.4 \mathrm{~mm})$, in partial substitution of the limestone filler, considering the $1.1 \%$ by the weight of the aggregates. Based on previous studies, the optimum bitumen content (Superpave-based method) was selected according to the $7.5 \%$ by the weight of the aggregates' mixture. Table 1 presents the rheological properties of the adopted PmB bitumen. Based on the same grading distribution and bitumen content, a reference SMA without CR (named SMA0) was produced as control mixture for the analysis of the rubber effect within the bituminous mixture.

Table 1. Conventional properties of the original bitumen.

\begin{tabular}{cccc}
\hline Property & Unit & Characteristic Value & Standard \\
\hline Penetration $@ 25^{\circ} \mathrm{C}$ & $\mathrm{dmm}$ & $25-55$ & EN 1426 \\
Softening Point & ${ }^{\circ} \mathrm{C}$ & 70 & EN 1427 \\
Force Ductility test $@ 10^{\circ} \mathrm{C}$ & $\mathrm{J} / \mathrm{cm}^{3}$ & 3 & EN 13589 \\
Dynamic Viscosity $@ 160^{\circ} \mathrm{C}$ & $\mathrm{Pa} \cdot \mathrm{s}$ & $0.4-0.7$ & EN 12596 \\
Elastic Recovery $@ 25^{\circ} \mathrm{C}$ & $\%$ & 80 & EN 13398 \\
\hline
\end{tabular}

\subsection{Mortar Mix Design}

The same PmB bitumen described in Table 1 was used for the production of the mortars. The CR and the limestone filler were the same used for the SMA mixture. In order to define the mortar grading distribution, the SMA grading curve, described in the previous paragraph, was normalized to the particle percentages below $2 \mathrm{~mm}$. The total material passing the $2 \mathrm{~mm}$ sieve was considered as $100 \%$ and therefore the other sieves have been normalized. Consequently, the bitumen and CR percentages were calculated based on the aggregate weight. The normalized fine aggregates passing the $2 \mathrm{~mm}$ sieve (Table 2) was calculated as follows:

$$
\text { PFAN }_{\mathrm{i}}=\frac{\mathrm{TP}_{\mathrm{i}} \cdot 100}{\mathrm{TP}_{2 \mathrm{~mm}}}
$$

where:

- $\quad P F A N_{i}$ is the normalized passing fine aggregate;

- $\mathrm{TP}_{\mathrm{i}}$ is the total passing for each sieve;

- $\mathrm{TP}_{2 \mathrm{~mm}}$ is the total passing the $2 \mathrm{~mm}$ sieve. 
Table 2. Normalized stone mastic asphalt (SMA) grading curve.

\begin{tabular}{ccc}
\hline Sieve Size [mm] & Total Passing [\%] & Passing [\%] Normalized [2 mm] \\
\hline 10 & 100.0 & $/$ \\
8 & 97.5 & $/$ \\
6 & 82.8 & $/$ \\
4 & 40.1 & 100.0 \\
2 & 24.8 & 79.84 \\
1 & 19.8 & 64.74 \\
0.5 & 16.8 & 54.03 \\
0.25 & 13.4 & 43.95 \\
0.125 & 10.9 & 36.29 \\
0.063 & 9.0 & \\
\hline
\end{tabular}

At the same time, for the production of mortars with the correct mixture components' amounts, normalized dosages of bitumen, fine $\mathrm{CR}$ and limestone filler were needed. The following equations were adopted:

$$
\begin{aligned}
& \mathrm{B}_{\mathrm{FA}}=\mathrm{B}_{\mathrm{A}} \cdot \frac{100}{\mathrm{TP}_{2 \mathrm{~mm}}} \\
& \mathrm{R}_{\mathrm{FA}}=\mathrm{R}_{\mathrm{A}} \cdot \frac{100}{\mathrm{TP}_{2 \mathrm{~mm}}} \\
& \mathrm{~F}_{\mathrm{FA}}=\mathrm{F}_{\mathrm{A}} \cdot \frac{100}{\mathrm{TP}_{2 \mathrm{~mm}}}
\end{aligned}
$$

where:

- $\quad \mathrm{B}_{\mathrm{FA}}$ is the bitumen percentage of fine aggregates;

- $\mathrm{R}_{\mathrm{FA}}$ is the rubber percentage of fine aggregates;

- $\mathrm{F}_{\mathrm{FA}}$ is the filler percentage of fine aggregates;

- $\mathrm{B}_{\mathrm{A}}$ is the bitumen percentage of total aggregates;

- $\mathrm{R}_{\mathrm{A}}$ is the rubber percentage of total aggregates;

- $\mathrm{F}_{\mathrm{A}}$ is the filler percentage of total aggregates.

All the components of the mortar mixture were normalized as follows:

- $\quad \mathrm{FA}_{\mathrm{FA}}(\mathrm{i}-\mathrm{j})$ is normalized fine aggregates retained between sieves (i-j) percentage (except for the filler);

- $\quad \mathrm{FA}_{m}(\mathrm{i}-\mathrm{j})$ is the fine aggregates retained between sieves $(\mathrm{i}-\mathrm{j})$ percentage (except for the filler) on mortar.

The single components were obtained through Equations (5)-(8).

$$
\begin{gathered}
\mathrm{B}_{\mathrm{m}}=\frac{\mathrm{B}_{\mathrm{FA}}}{\sum \mathrm{FA}_{\mathrm{FA}}(\mathrm{i}-\mathrm{j})+\mathrm{F}_{\mathrm{FA}}+\mathrm{B}_{\mathrm{FA}}+\mathrm{R}_{\mathrm{FA}}} \\
\mathrm{R}_{\mathrm{m}}=\frac{\mathrm{R}_{\mathrm{FA}}}{\sum \mathrm{FA}_{\mathrm{FA}}(\mathrm{i}-\mathrm{j})+\mathrm{B}_{\mathrm{FA}}+\mathrm{R}_{\mathrm{FA}}+\mathrm{F}_{\mathrm{FA}}} \\
\mathrm{F}_{\mathrm{m}}=\frac{\mathrm{F}_{\mathrm{FA}}}{\sum \mathrm{FA}_{\mathrm{FA}}(\mathrm{i}-\mathrm{j})+\mathrm{B}_{\mathrm{FA}}+\mathrm{R}_{\mathrm{FA}}+\mathrm{F}_{\mathrm{FA}}} \\
\left.\mathrm{FA}_{\mathrm{m}}(\mathrm{i}-\mathrm{j})=\frac{\mathrm{FA}}{\sum \mathrm{FA}_{\mathrm{FA}}(\mathrm{i}-\mathrm{j})} \mathrm{j}\right)+\mathrm{B}_{\mathrm{FA}}+\mathrm{R}_{\mathrm{FA}}+\mathrm{F}_{\mathrm{FA}}
\end{gathered}
$$

The amount of limestone filler $\left(\mathrm{F}_{\mathrm{m}}\right)$, bitumen $\left(\mathrm{B}_{\mathrm{m}}\right)$ and $\mathrm{CR}\left(\mathrm{R}_{\mathrm{m}}\right)$ were calculated using the described normalization method, as shown in Table 3. 
Table 3. Mortar percentage composition.

\begin{tabular}{ccccc}
\hline Mortar & Bitumen [\%] & Rubber [\%] & Filler [\%] & Fine Aggregate [\%] \\
\hline MORTAR-CR & 24.92 & 3.65 & 16.95 & 55.93 \\
\hline
\end{tabular}

The mortars production operations were fixed uniquely for every sample. Before starting the mixing, fine aggregates were stored in the oven at $160^{\circ} \mathrm{C}$ in order to achieve dry conditions. The mixing temperature $\left(160^{\circ} \mathrm{C}\right)$ was controlled regularly during hand mixing of the mortar samples. The fine aggregates were first poured into the mixing pot, the PMB binder was added and finally the fine CR was added to the mixture. The obtained mortar was hand mixed for $5 \mathrm{~min}$. A specific mould for mortars (Table 4, Figure 1) was adopted to produce the samples. Once extracted, the samples were stored at $5{ }^{\circ} \mathrm{C}$ to preserve their properties and shapes.

Table 4. Mould characteristics.

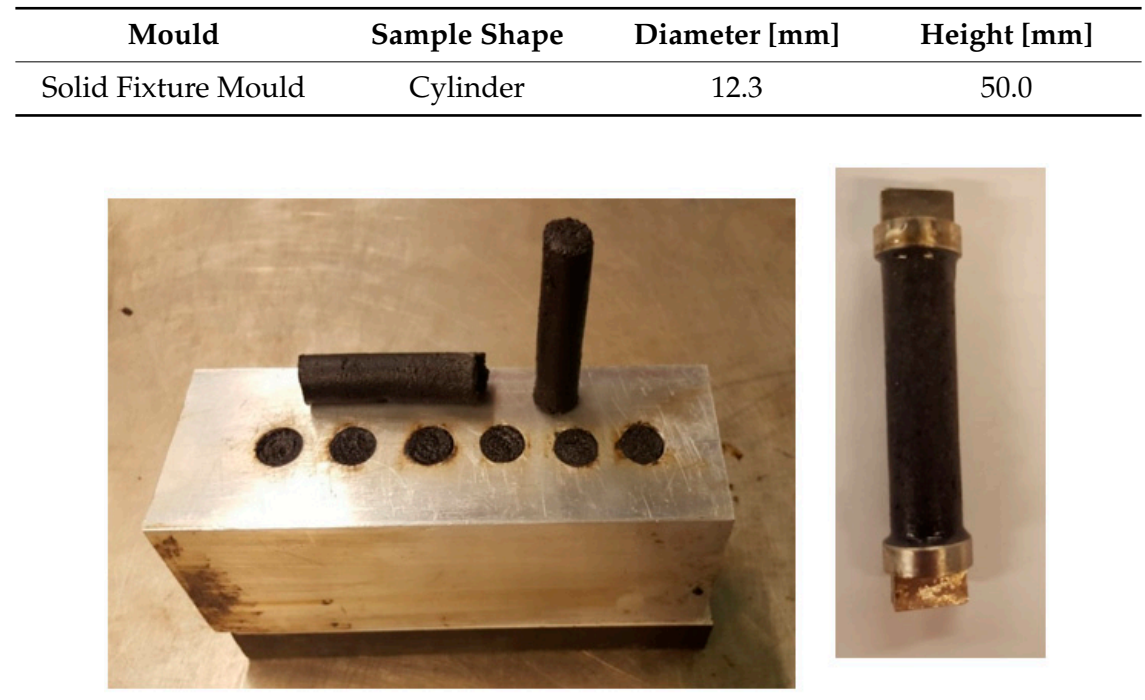

Figure 1. Steel mould and extracted mortar sample.

\subsection{Mastic Mix Design}

As for the mastics, PMB bitumen, limestone filler and fine CR were mixed together. Starting from the SMACR, the mastics were produced based on the normalized dosages, as calculated for the mortars. The mastics were designed by mixing all the components with proportions related to their weight of the aggregate mixture (Table 5).

Table 5. Mastic percentage composition (by weight).

\begin{tabular}{cccc}
\hline Mastic & Bitumen [\%] & Rubber [\%] & Filler [\%] \\
\hline MASTIC-CR & 59.52 & 8.73 & 31.75 \\
\hline
\end{tabular}

\section{Methods}

\subsection{SMAs DTC Stiffness Modulus Test}

The stiffness moduli of the mixtures were analyzed following the EN 12697-26, part D Standard. According to the direct tension-compression (DTC) setting, a cylindrical specimen is subject to a sinusoidal strain with an amplitude $\varepsilon 0 \leq 25 \mu$ strain. The calculated complex modulus depends on the selected temperature and frequency. To have enough data to present the master curve of the material, the standard suggests that the complex modulus shall be evaluated according to at least 4 temperatures and 3 frequencies for each temperature. 


\subsection{Mortar Frequency Sweep Test}

Mortar samples were tested using a solid fixture configuration for torsional loading. The adopted rheometer was equipped with an active hood to reach the selected temperature in the chamber (Figure 2). The samples stored at $5{ }^{\circ} \mathrm{C}$ were conditioned at the room temperature (around $25^{\circ} \mathrm{C}$ ) for an hour before being tested, to avoid rapid variation in the sample temperature. Instant adhesive glue was applied on the disposable plate and on both specimens' ends. To ensure an adequate bond, additional glue was applied around the circumference of the specimen edges and plates. The mortar sample was clumped to the solid fixture by two bolts before installing the whole system in the rheometer.
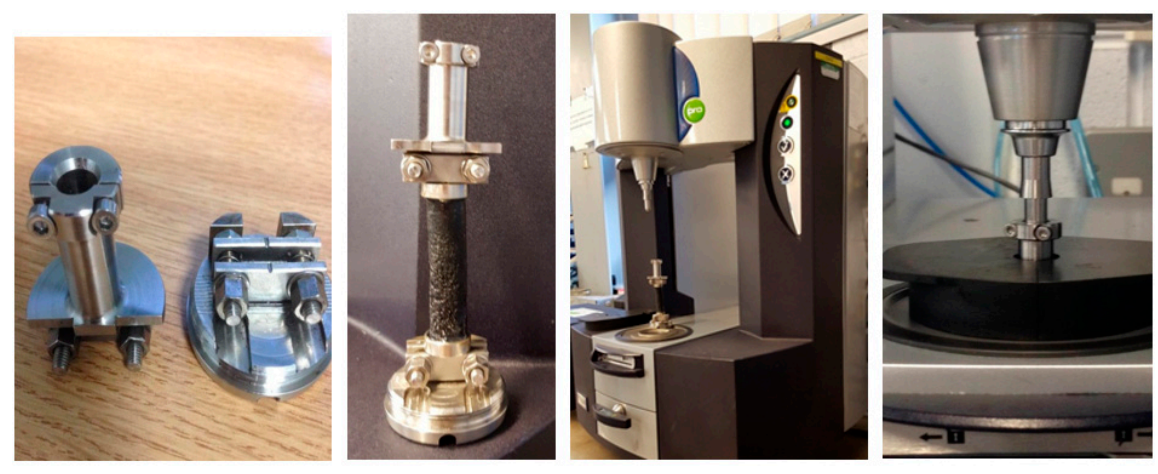

Figure 2. Mortar samples installation and test configuration.

Dynamic mechanical analysis, based on oscillatory tests, was carried out on the mortar sample to evaluate its rheological properties. The tests were performed under controlled strain, and its amplitude was limited within the linear visco-elastic (LVE) response of the specimen (strain level of $0.0065 \%$ ). Data were obtained from frequency sweep tests between 0.01 and $10 \mathrm{~Hz}$, performed between 10 and $60{ }^{\circ} \mathrm{C}$. The sample was conditioned for $30 \mathrm{~min}$ for each temperature to allow the internal temperature equilibrium. The mortars rheological parameters evaluated from this test were the phase angle $\delta$ and the complex shear modulus $G^{*}$.

\subsection{Mastic Frequency Sweep Test and Time Sweep Test}

Amplitude sweep (AS) tests were preliminarily performed to evaluate the viscoelastic region at $10{ }^{\circ} \mathrm{C}$, applying a constant frequency of $10 \mathrm{rad} / \mathrm{s}(1.59 \mathrm{~Hz})$. The investigated strain level was in the range between $0.01 \%$ and $100 \%$ of mastic deformation. The selected strain amplitude was related to a variation of the complex modulus below the $10 \%$ of its initial value. A dynamic mechanical analysis based on oscillatory tests carried out with a dynamic shear rheometer (DSR) were performed to determine mastic's rheological properties. The tests were performed considering a controlled strain, and the strain amplitude was limited within the LVE behavior of the mastic. Frequency sweep tests were carried out between 0.01 and $10 \mathrm{~Hz}$, in a temperature range between 10 and $60^{\circ} \mathrm{C}$. The $8 \mathrm{~mm}$ measurement system with $2 \mathrm{~mm}$ gap was chosen in every temperature range. Furthermore, a time sweep (TS) test was performed in order to study the mastic healing. In this case, the tests were carried out adding a $1 \mathrm{~h}$ rest period when the $\mathrm{G}^{*}$ modulus reached a $35 \%$ reduction when compared to its value calculated in the previous test without rest period. Two repetitions for each stress level were performed in order to verify its repeatability.

\subsection{Indirect Tensile Fatigue Test}

The fatigue behavior of the SMA was studied according to the indirect tensile fatigue test (ITFT, EN 12697-24 Annex E standard). According to the Standard, the durability of a cylindrical shaped specimen is evaluated in terms of resistance when subject to repeated compressive loads through its vertical diametrical plane. The fatigue life is measured as the number of load applications that meet defined failure criteria. In the case under study, it is defined as the halving of the stiffness 
modulus measured at 100 cycles. The fatigue life of a material is based on tests carried out considering three different levels of stress. In this research, the horizontal stress levels were fixed equal to 150, 200 and $250 \mathrm{kPa}$. For each mixture, three specimens were tested for every single stress level at $20^{\circ} \mathrm{C}$.

\section{Results analysis}

\subsection{SMAs DTC Stiffness Modulus Analysis}

For SMAs DTC stiffness modulus test, four $100 \mathrm{~mm}$ diameter SGC (superpave gyratory compactor) specimens (EN 12697-31, 75 gyrations) were prepared. The selected temperatures were 10, 20, 30 and $40{ }^{\circ} \mathrm{C}$. Six frequencies were adopted for each temperature: $0.3,0.6,1,3,10$ and $20 \mathrm{~Hz}$. Before being tested, each sample was kept at the test temperature for $4 \mathrm{~h}$. For a clearer interpretation of results, a volumetric analysis based on the evaluation of the air voids content (EN 12697-8) of the SMACR samples was carried out. Results are presented in Table 6.

Table 6. Air voids content and density for SMA-crumb rubber (CR).

\begin{tabular}{ccccc}
\hline Mixture & Va [\%] & AVG Va [\%] & $\rho\left[\mathrm{g} / \mathrm{cm}^{3}\right]$ \\
\hline SMACR_1 & 6.03 & & \multirow{2}{*}{5.59} & 2.376 \\
\cline { 1 - 2 } SMACR_2 & 5.50 & & \\
\hline SMACR_3 & 5.26 & & \\
\hline
\end{tabular}

Results show an average air void content equal to $5.59 \%$ for SMACR, which is in line with the values suggested by the adopted Italian technical specifications for this type of AC.

Figure 3 shows the average DTC stiffness moduli for the experimental SMA with CR.

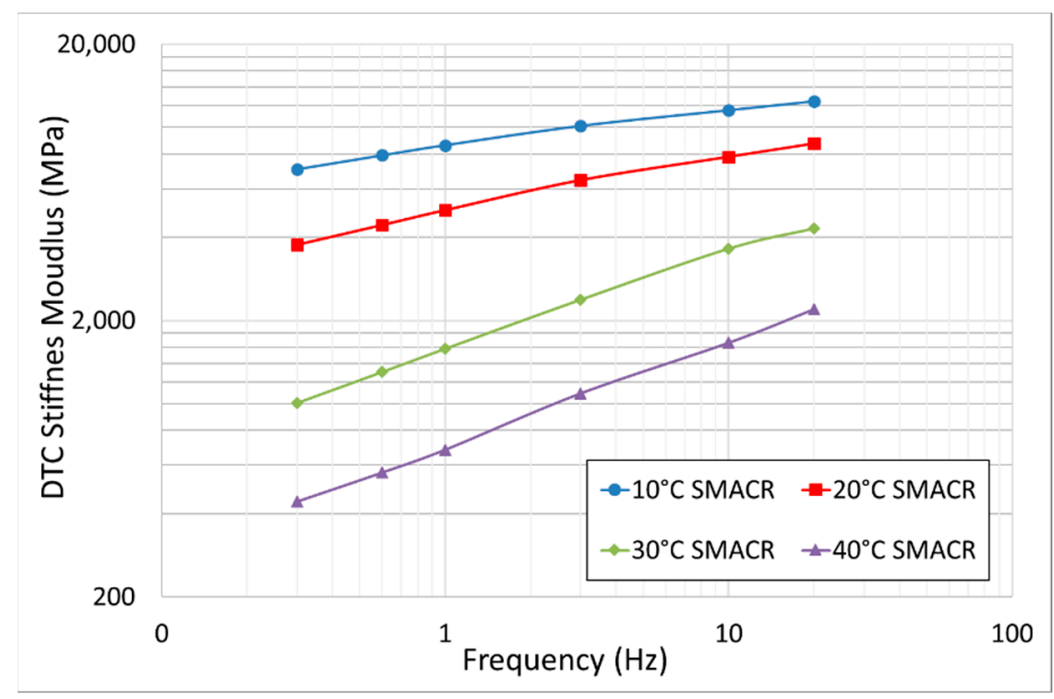

Figure 3. Direct tension-compression (DTC) Isothermal curves for SMACR.

As a general result, the stiffness moduli comply with values traditionally suggested by the Italian technical specifications for this SMA (Stiffness Modulus $>3500 \mathrm{MPa}$ at $20^{\circ} \mathrm{C}$ ). Extending the use of the time-temperature superposition (TTS) principle, which represents the theoretical basis for the rheological analysis of a bitumen in the linear field [21], a single DTC master curve can calculated to show the SMACR behavior in terms of stiffness. Using the calculated time-temperature shift factors (TTsf) shown in Table 7, it is possible to translate data at different temperatures along the time axis to create a unique master curve that refers to a specific temperature. In the case under study, the reference temperature was $20^{\circ} \mathrm{C}$. 
Table 7. Time-temperature shift factors (TTsf) DTC master curve at $20^{\circ} \mathrm{C}$.

\begin{tabular}{cc}
\hline Temperature $\left[{ }^{\circ} \mathbf{C}\right]$ & TTsf \\
\hline 40 & 0.0031 \\
30 & 0.0249 \\
20 & 1 \\
10 & 16.0799 \\
\hline
\end{tabular}

The SMACR DTC master curve at $20{ }^{\circ} \mathrm{C}$, obtained with the aforementioned TTsf using the traditional Williams-Landel-Ferry (WLF) model, is presented in Figure 4.

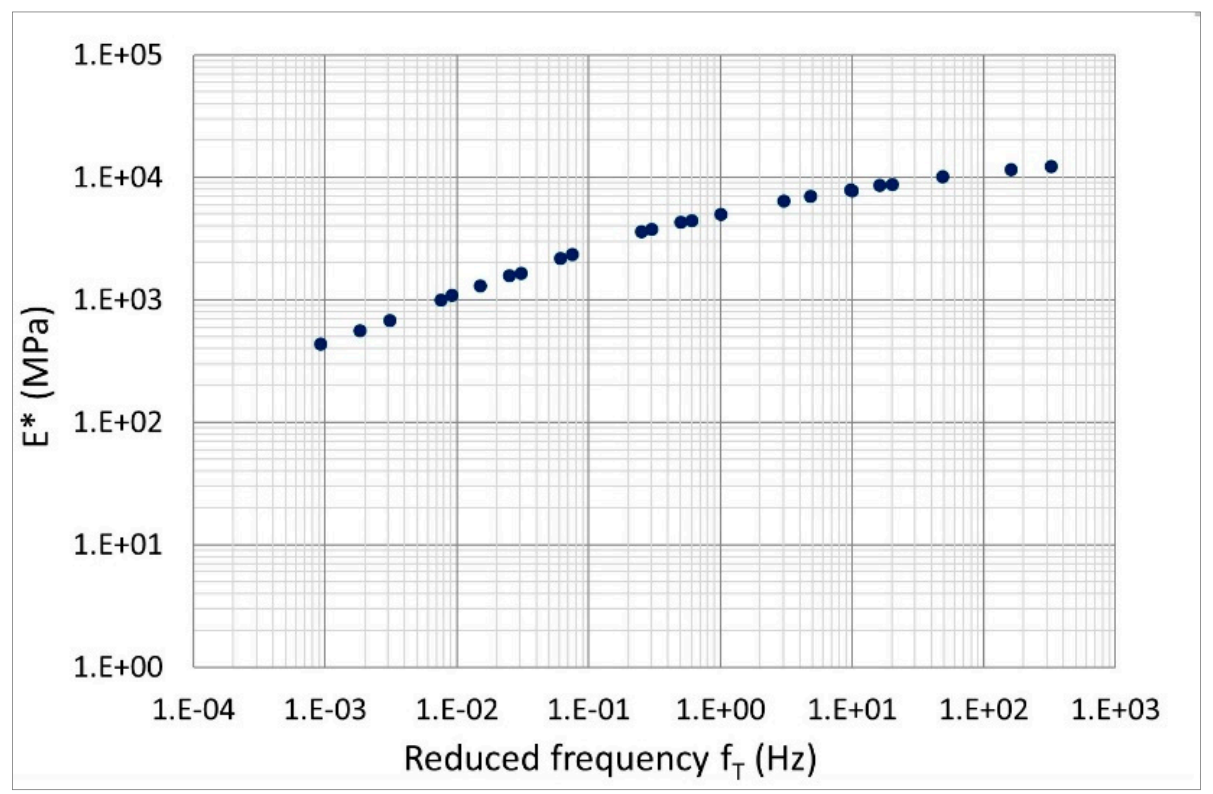

Figure 4. SMACR master curve at $20^{\circ} \mathrm{C}$.

\subsection{Mortar Frequency Sweep Test Analysis}

It is worth underlining that the air void content affects the AC mixtures mechanical behavior and, as observed by Underwood et al. [19], a similar phenomenon is also visible on FAM mixtures. Therefore, having this study as reference the bituminous matrix of a gap graded SMA mixture, the objective was to obtain a FAM mixture with an air void content below $2 \%$. Results presented in Table 8 verify an air voids content lower than $2 \%$ for the produced mortars.

Table 8. Air voids content and density for MORTAR-CR.

\begin{tabular}{ccc}
\hline Mortar & Va [\%] & $\rho\left[\mathrm{g} / \mathrm{cm}^{3}\right]$ \\
\hline MORTAR-CR & 1.82 & 1.831 \\
\hline
\end{tabular}

Figure 5 shows the isothermal curves for the MORTAR-CR.

The mortar master curve was created applying the time-temperature superposition principle and the WLF theory. Data were analyzed based on the assumption of FAM thermos-rheological simplicity. As done for the SMACR, the isothermal curves were shifted horizontally to construct the MORTAR-CR master curve at $20^{\circ} \mathrm{C}$. The used shift factors (TTsf) are presented in Table 9. 


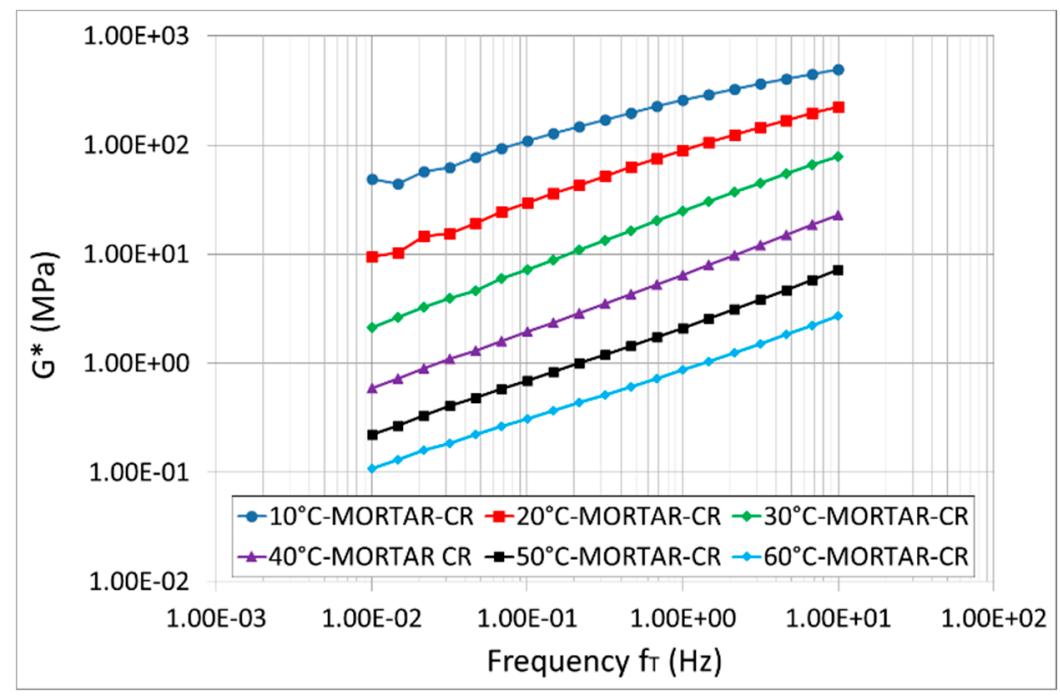

Figure 5. Isothermal curve for MORTAR-CR.

Table 9. TTsf for MORTAR-CR master curve at $20^{\circ} \mathrm{C}$.

\begin{tabular}{cc}
\hline Temperature $\left[{ }^{\circ} \mathbf{C}\right]$ & TTsf \\
\hline 60 & 0.000113427 \\
50 & 0.000570256 \\
40 & 0.004372202 \\
30 & 0.068937137 \\
20 & 1 \\
10 & 16.23437893 \\
\hline
\end{tabular}

The TTS principle is valid also in the case of bituminous mortar, as demonstrated by the continuous master curve trends (Figure 6).

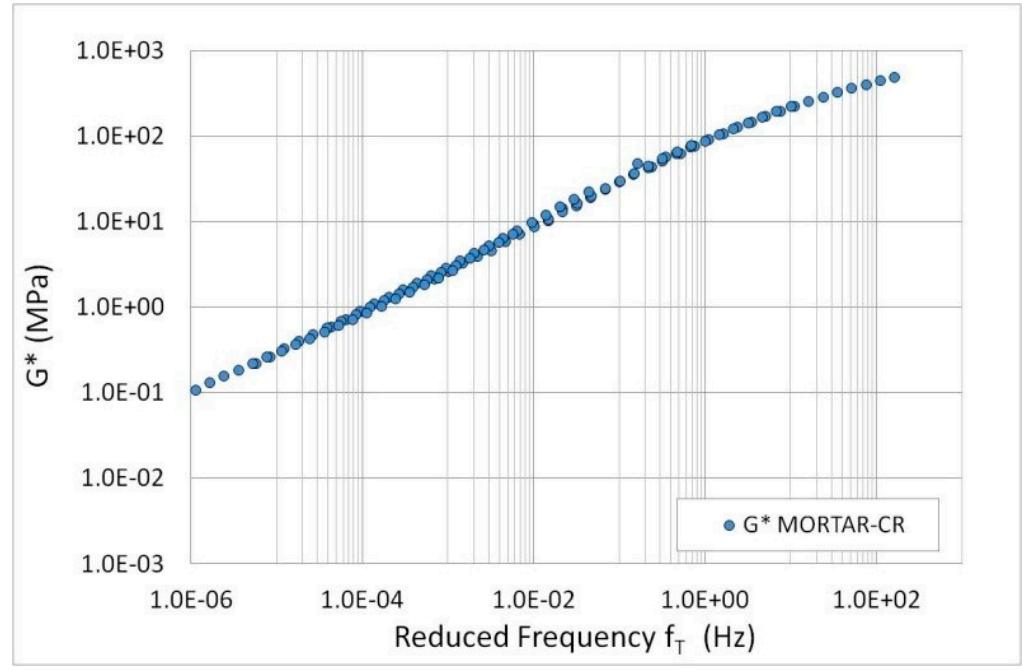

Figure 6. MORTAR-CR master curve at $20^{\circ} \mathrm{C}$.

\subsection{Mastic Frequency Sweep Test results}

In compliance with the mortar rheological analysis, in the mastic investigation the TTS principle was applied to create the $\mathrm{G}^{*}$ master curve at $20^{\circ} \mathrm{C}$ (Figure 7 ). 


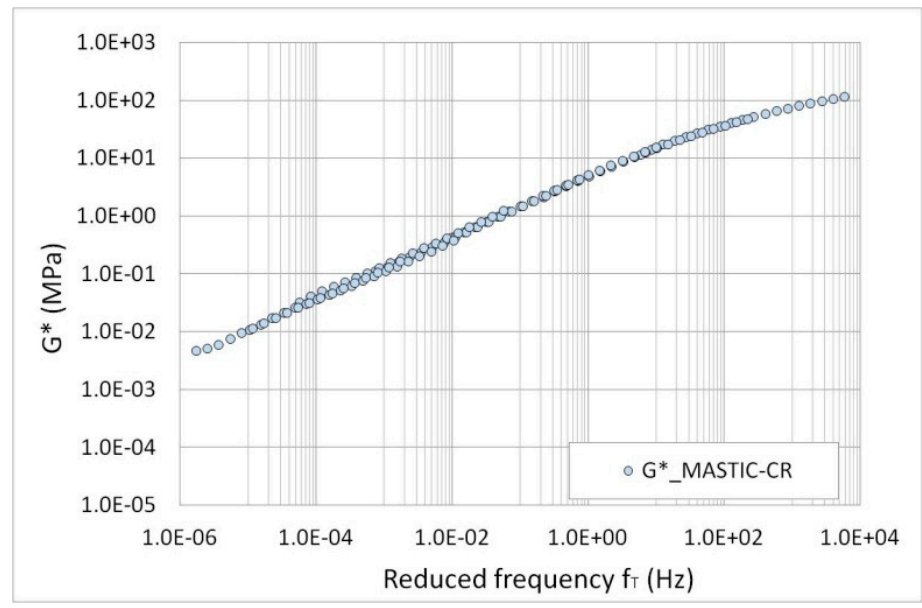

Figure 7. MASTIC-CR master curve at $20^{\circ} \mathrm{C}$.

Table 10 shows the TTsf used for the master curve construction.

Table 10. TTsf for MASTIC-CR master curve at $20^{\circ} \mathrm{C}$.

\begin{tabular}{cc}
\hline Temperature $\left[{ }^{\circ} \mathbf{C}\right]$ & TTsf \\
\hline 60 & 0.00017018 \\
50 & 0.001043079 \\
40 & 0.005653233 \\
30 & 0.074385949 \\
20 & 1 \\
10 & 21.98403888 \\
\hline
\end{tabular}

\section{Discussion}

\subsection{Multiscale Model Validation}

As shown in Figure 8 the $\mathrm{G}^{*}$ master curves for mortar and mastic have a very similar trend, although shifted.

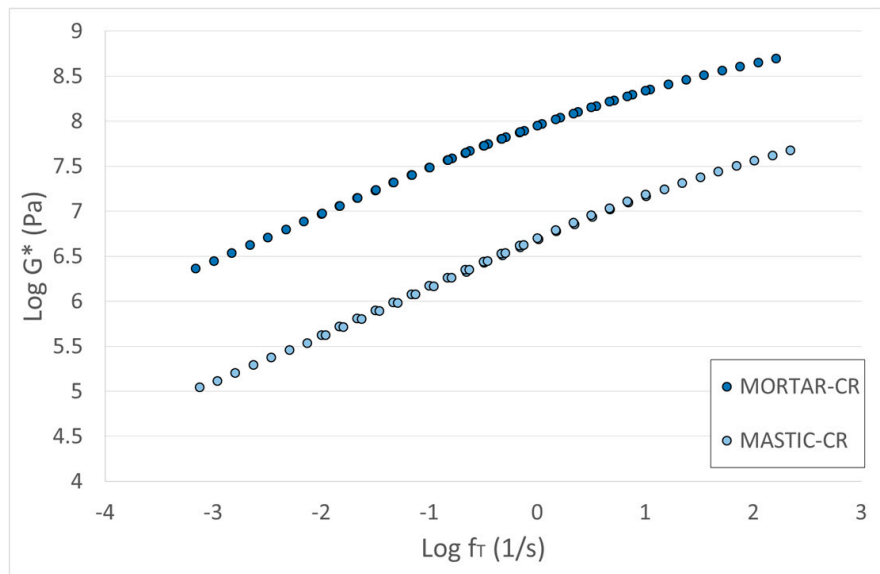

Figure 8. MORTAR-CR and MASTIC-CR master curves.

This result confirms that the proportion of every single components of the mortar and mastic mix design has been correctly calculated and that the rheological behavior of the mortar (master curve slope) is linked to the rheological behavior of the mastic. The increase in the stiffness from mastic to the mortar is due to the presence of a solid skeleton made of fine aggregates and limestone filler. The same effect is visible in Figure 9 adding the mixture master curve. 


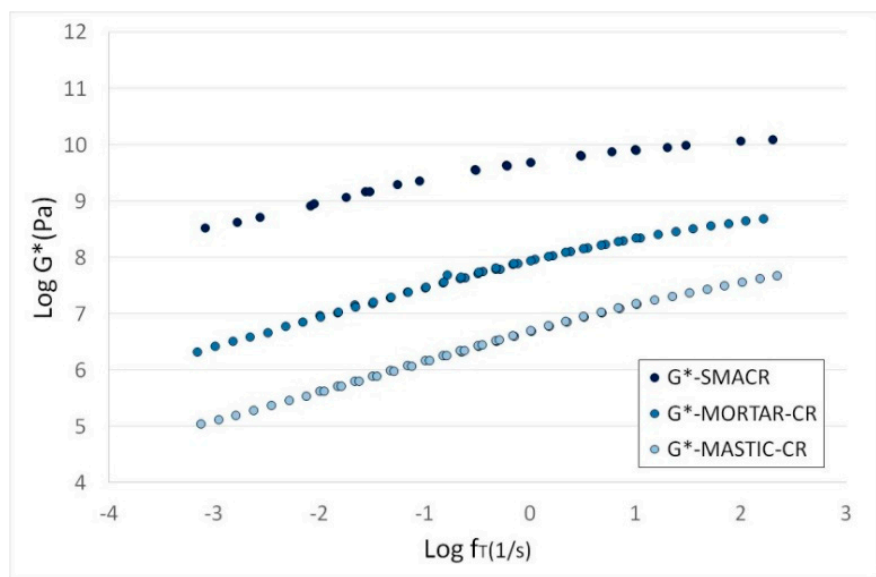

Figure 9. SMACR, MORTAR-CR and MASTIC-CR master curves.

The same overall characteristics of the SMACR mixture are evident both in the MASTIC-CR and MORTAR-CR materials. In particular, the S-shaped master curve function is visible for every scale level and it is further confirmed fitting the well-known sigmoidal model (Figure 10).

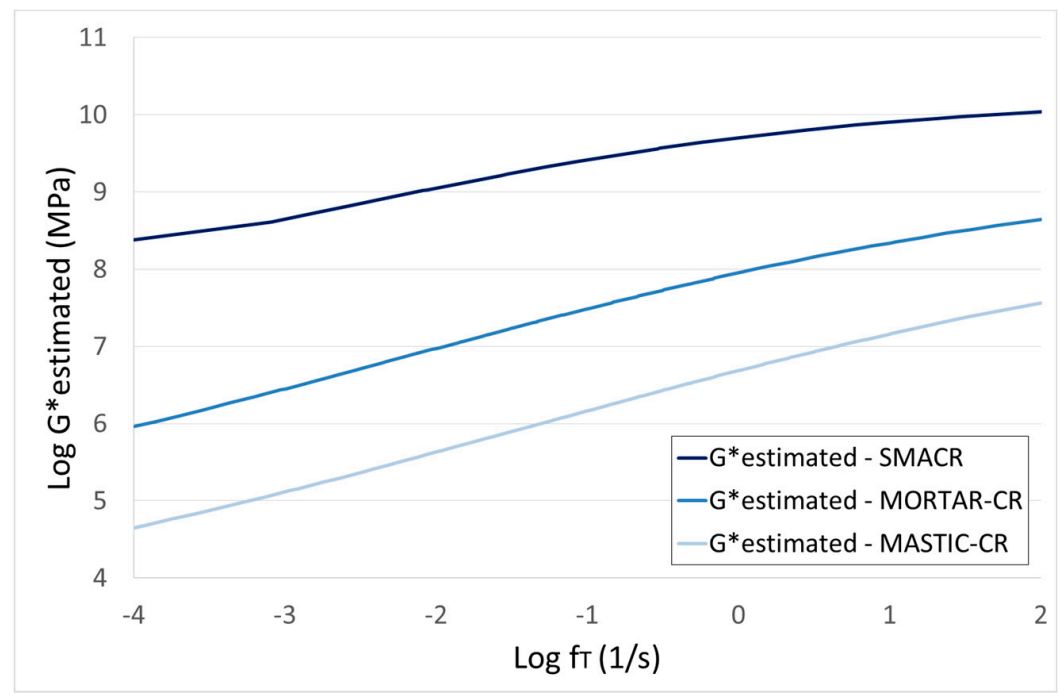

Figure 10. Sigmoidal model master curves.

In case of the sigmoidal model defined by Equation (9), it can be fitted on the dynamic modulus vs. frequency plane:

$$
\log \left(\mathrm{G}^{*}\right)=\delta+\frac{\mathrm{a}}{1+\mathrm{e}^{\beta+\gamma(\log \omega)}}
$$

where:

- $\log (\omega):$ logarithmic reduced frequency;

- $\delta$ : lower asymptote;

- $\quad \beta$ e $\gamma$ : shape factors between the asymptotes and the local inflection points (points corresponding to a frequency $\omega=10-\beta / \gamma)$.

The fitting issue was solved using the least-squares method implemented in MATLAB that allows the solution of the minimization problem through a sigmoidal function. The mathematical modelling of the complex modulus has allowed the estimation of mastic, mortar and mixture behavior in a wider range of frequencies, providing numerical parameters to compare the mastic combinations (Table 11). 
Table 11. Sigmoidal complex modulus model parameters.

\begin{tabular}{ccccc}
\hline Sample Length Scale & $\alpha$ & $\beta$ & $\delta$ & $\gamma$ \\
\hline SMACR & -2.817 & 1.473 & 10.230 & -0.572 \\
MORTAR-CR & -5.038 & 0.921 & 9.386 & -0.410 \\
MASTIC-CR & -5.731 & 0.532 & 10.240 & -0.380 \\
\hline
\end{tabular}

Another validation of this multiscale approach is shown in Figure 11 and it is related to the existence of a similar TTsf shift factors function for mastic, FAM and AC.

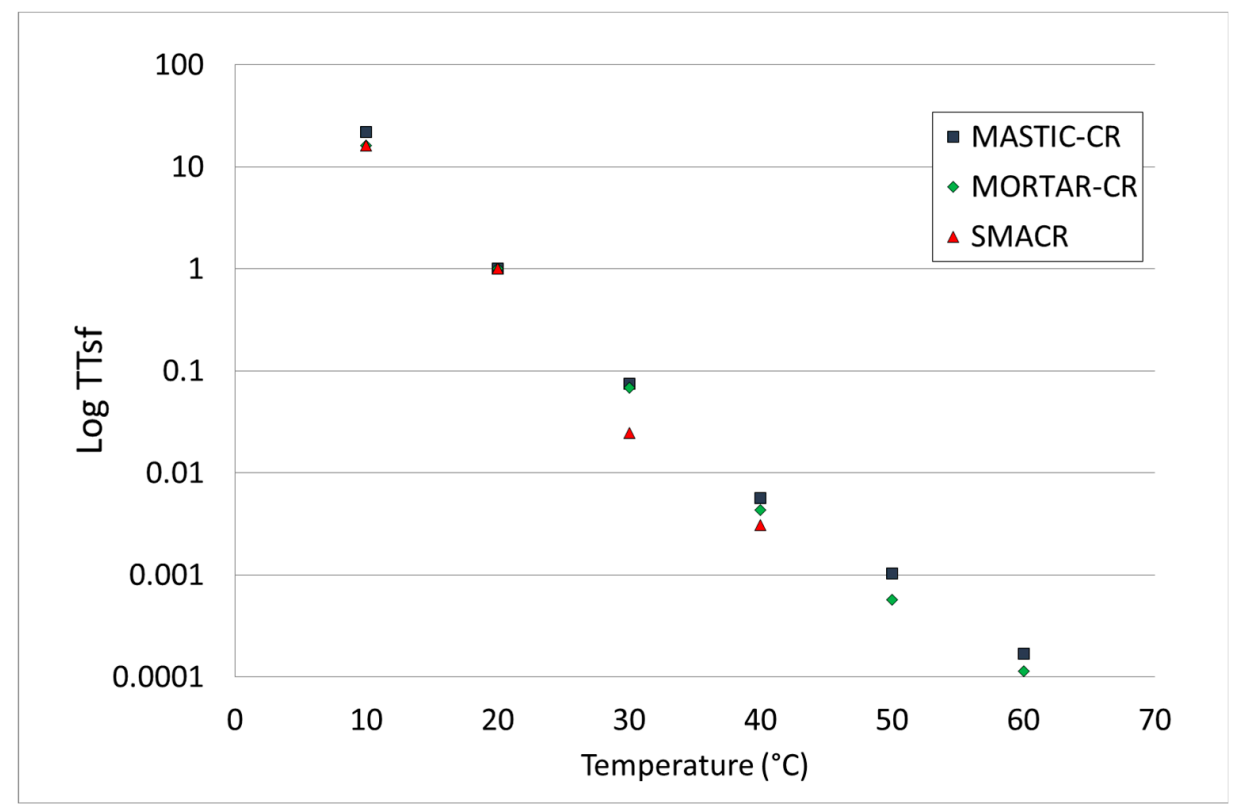

Figure 11. LogTTsf-Temperature function.

\subsection{Rubber Effects}

Once shown the results of the multi-scale approach for the bituminous mixtures containing fine $\mathrm{CR}$, the rubber effects were analyzed comparing the MASTIC-CR, MORTAR-CR and SMACR with the corresponding bituminous mixtures containing only limestone filler. Once again, starting from a traditional SMA mixture without CR (SMA0), the dosages of the mastic (MASTIC-SMA) and mortar (MORTAR-SMA) components were calculated using the same normalization method showed in the previous paragraphs.

Results in Figure 12 show that, considering the mastic and mortar scale of analysis, the combined presence of limestone filler and $C R$ reduces the $G^{*}$ values if compared to the traditional SMA mastic and mortar at high frequencies (low temperatures). At the same time, $\mathrm{G}^{*}$ values at low frequencies (high temperatures) are registered for the bituminous mixture with limestone filler and CR.

Thus, it can be stated that the CR effects on the rheo-mechanical behavior can be translated to a reduction in the bitumen thermo-sensitivity. In particular, considering the mastic and mortar scales, the fine CR acts mainly at low temperatures (high frequencies) limiting the stiffness and therefore the possible thermal cracking proneness of the bituminous mastic.

All in all, the addition of $\mathrm{CR}$ reduces the thermo-sensitivity of mastic, mortar and mixture but this effect is not the exactly the same for all the scale of analysis. While in the mortar, the CR effect is mainly visible at low temperatures, in the mastic scale a small variation in stiffness is registered also at high temperatures. This increase in stiffness is amplified at the mixture scale. The SMACR master curve shows a relevant increase in the stiffness at high and medium temperatures. This is a further confirmation of the influence of the aggregates' matrix size in the rubber-bitumen-aggregates interaction. 


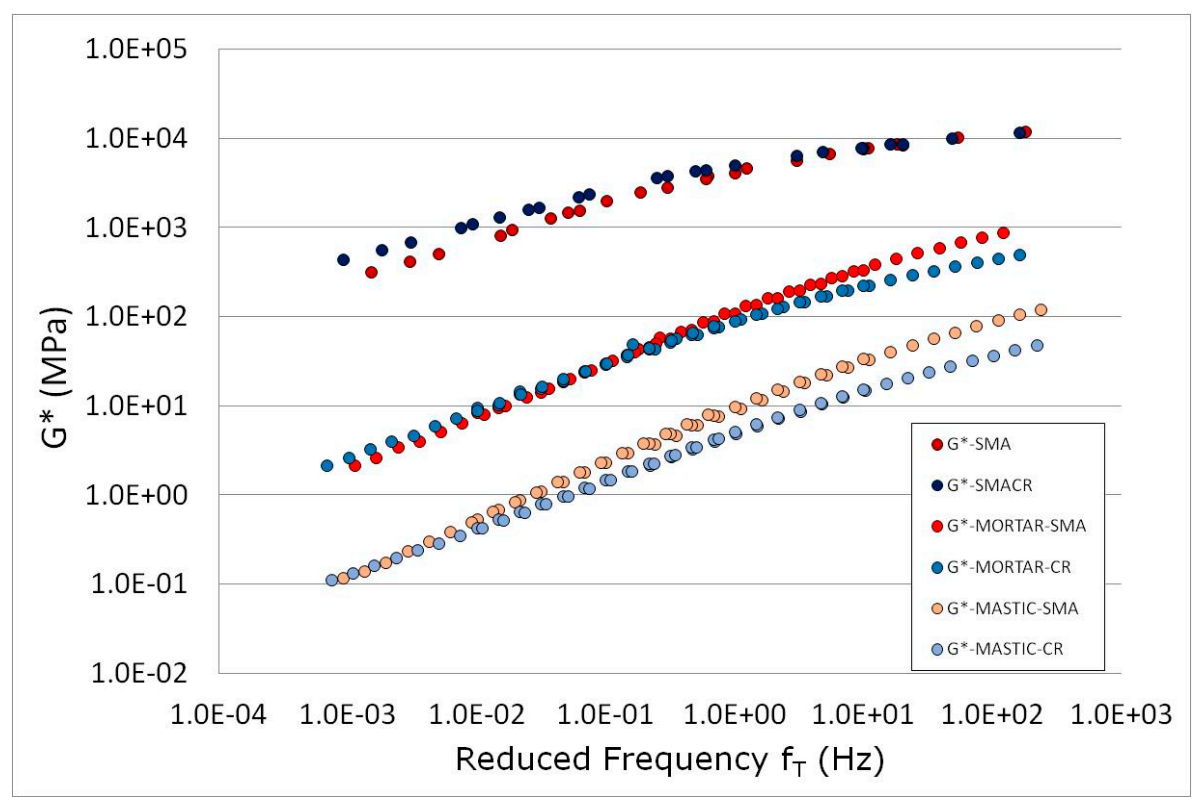

Figure 12. Master curves comparison between mixture, mortar and mastic containing $C R$ or not.

Considering the mixtures without rubber, the $\mathrm{CR}$ effects tend to be shifted from low to high temperatures when the coarser aggregates are progressively added to the bituminous mixtures. In order to validate these results in terms of mixture fatigue life, the durability of the bituminous mixtures with and without $\mathrm{CR}$ was assessed on mastics and mixtures. In particular, the healing of the mastics was evaluated with TS tests, while fatigue tests were carried out on SMA mixtures. The adopted test configuration for the TS tests is explained in Paragraph 3.3 and the results are given in terms of shear strain $(\gamma)$.

The fatigue behavior of the SMA was investigated in order to deeply investigate the effect of the rubber according to the Dry Hybrid technology within the bituminous mixtures. Results for mastics and mixtures are presented in Figures 13 and 14.

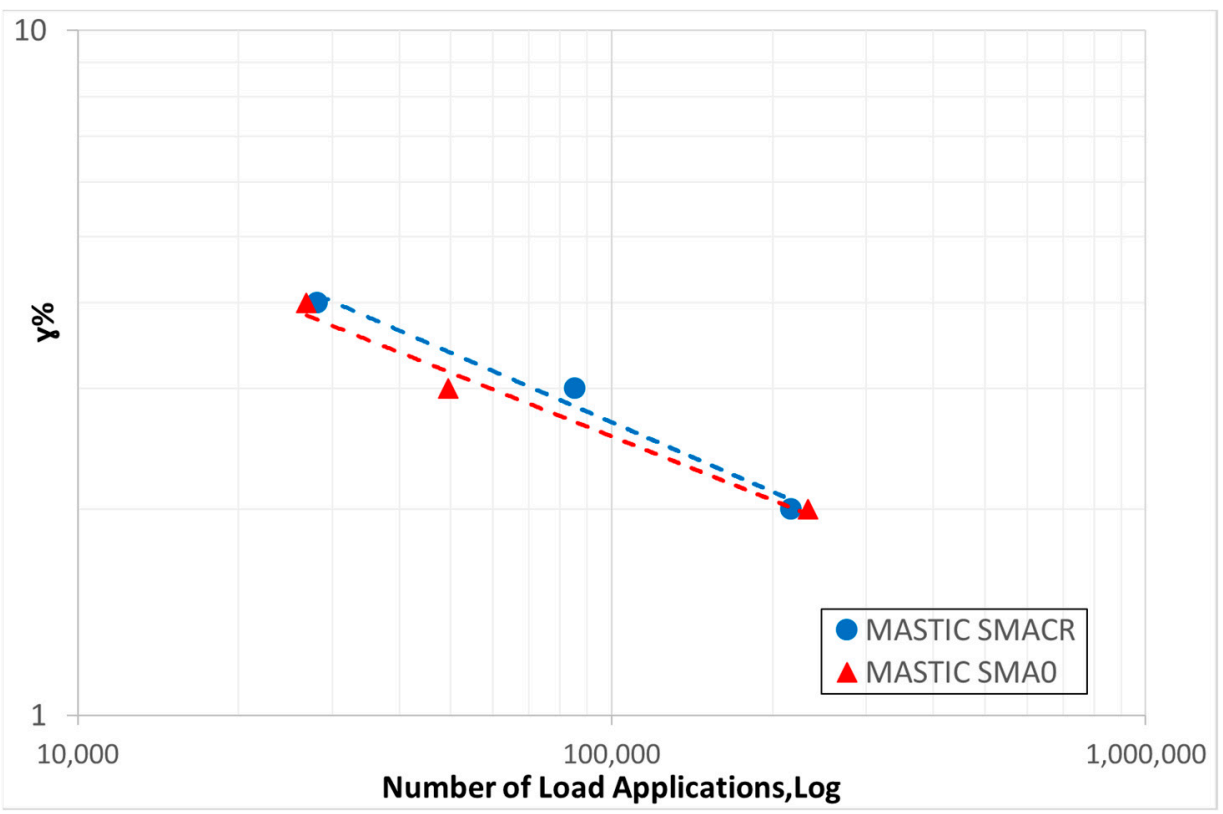

Figure 13. Mastics time sweep test comparison. 


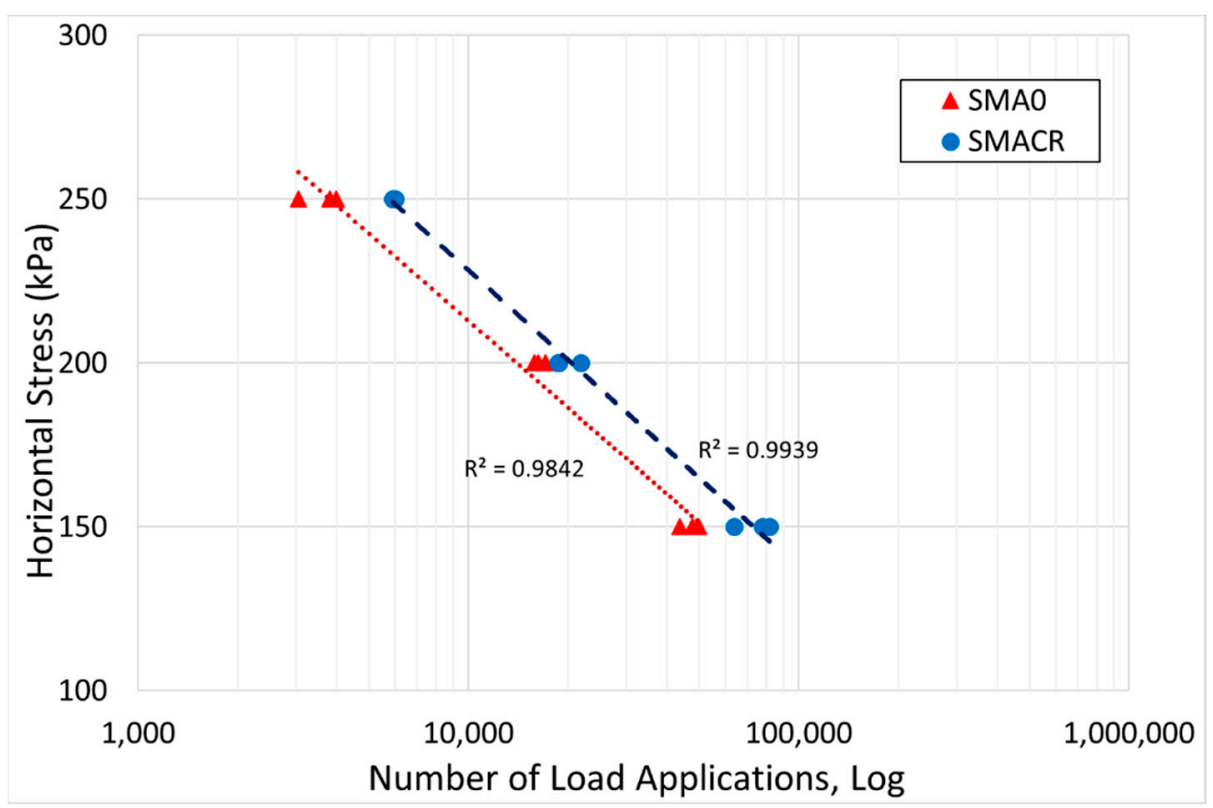

Figure 14. Mixtures indirect tensile fatigue test (ITFT) test comparison.

From the analysis of results, the increase in number of load applications for both SMACR mastic and mixture is clear. The presence of $\mathrm{CR}$ involves the improvement of mastic and mixture durability regardless the applied stress. The phenomenon is confirmed in terms of healing (TS test on mastics) and fatigue life (ITFT on mixtures).

It is worth noting that in terms of the stiffness modulus, both mixtures show comparable values (3259 MPa for SMACR and $3188 \mathrm{MPa}$ for SMA0 at $20^{\circ} \mathrm{C}$, calculated according to EN 12697-26 Annex $\mathrm{C}$ standard). In the light of the above, the adopted stress levels produced comparable horizontal deformations in the samples, validating the adopted test conditions.

\section{Conclusions}

The main objective of this study was to evaluate the rheo-mechanical properties of mastics, mortars and mixtures containing fine $\mathrm{CR}$ according to the dry-hybrid technology, through a multiscale approach. In particular from the obtained results the following conclusions can be drawn:

- The multi-scale approach allows a deep analysis of the rheo-mechanical behavior of bituminous mixtures. Mastic, mortar and mixture master curves characteristics confirm that the SMAs properties depend on mastics matrix, the coarse aggregates increase the stiffening and the fine $C R$ and limestone filler contribute to change the master curve slope;

- The interaction between fine CR and limestone filler provides higher stiffness to the mastic, mortar and mixture increasing the rutting parameters. The rubber, here used as partial replacement of filler, reduces the bituminous mixtures thermo-sensitivity at all scales. The combined action of both limestone filler and CR increases the stiffness and permanent deformations' resistance, reducing, at the same time, the material brittle behavior at low temperatures. This effect depends on the actual size of the aggregates matrix included in the mixture.

- Fatigues tests results can be considered as an additional confirmation of the mix design quality and follow the same trend verified in other researches on the positive influence of rubber in asphalt mastic and mixtures produce with the dry-hybrid technology.

The discussed data have confirmed that the adoption of the dry-hybrid technology provides the materials with high performances in terms of resistance to permanent deformations and thermal and fatigue cracking. This result was achieved analyzing the mixtures at different scales, confirming the 
validity of the multiscale model in the presence of the fine CR powder not only on LVE range, but also on repeated and high stress levels.

Author Contributions: Conceptualization, C.S. and F.M.; methodology, C.S. and F.M.; validation, C.S. and G.A.; investigation, F.M. and P.T.; resources, D.F.; data curation, F.M. and P.T;; writing —original draft preparation, F.M. and P.T.; writing - review and editing, F.M., P.T. and C.S.; supervision, C.S., A.S. and G.A.; funding acquisition, C.S. and D.F. All authors have read and agreed to the published version of the manuscript.

Funding: This research received no external funding.

Acknowledgments: Ecopneus Scpa supplied the crumb rubber during the whole research. Valli Zabban Spa and Frantoio Fondovalle Srl provided the bituminous mixtures for the laboratory analysis and built the trial field.

Conflicts of Interest: The authors declare no conflict of interest.

\section{References}

1. Wang, T.; Xiao, F.; Zhu, X.; Huang, B.; Wang, J.; Amirkhanian, S. Energy consumption and environmental impact of rubberized asphalt pavement. J. Clean. Prod. 2018, 180, 139-158. [CrossRef]

2. Carlson, D.D.; Zhu, H. Asphalt-Rubber An Anchor to Crumb Rubber Markets. Third Joint UNCTAD/IRSG Workshop on Rubber and the Environment; International Rubber Forum: VerTCRuz, Mexico, 1999.

3. Lo Presti, D. Recycled Tyre Rubber Modified Bitumens for road asphalt mixtures: A literature review. Construct. Build. Mater. 2013, 49, 863-881. [CrossRef]

4. Dondi, G.; Tataranni, P.; Pettinari, M.; Sangiorgi, C.; Simone, A.; Vignali, V. Crumb Rubber in cold recycled bituminous mixes: Comparison between Traditional Crumb Rubber and Cryogenic Crumb Rubber. Construct. Build. Mater. 2014, 68, 370-375. [CrossRef]

5. Subhy, A.; Pires, G.M.; Lo Presti, D.; Airey, G. The effects of laboratory ageing on rheological and fracture characteristics of different rubberised bitumens. Construct. Build. Mater. 2018, 180, 188-198. [CrossRef]

6. Thodesen, C.; Xiao, F.; Amirkhanian, S.N. Modeling viscosity behavior of crumb rubber modified binders. Construct. Build. Mater. 2009, 23, 3053-3062. [CrossRef]

7. Fornai, D.; Sangiorgi, C.; Mazzotta, F.; Bermejo, J.M.; Saiz, L. A new era for rubber asphalt concretes for the green public procurement in road construction. In Proceedings of the 1st European Road Infrastructure Congress, Leeds, UK, 18-20 October 2016.

8. Sangiorgi, C.; Tataranni, P.; Simone, A.; Vignali, V.; Lantieri, C.; Dondi, G. Stone mastic asphalt (SMA) with crumb rubber according to a new dry-hybrid technology: A laboratory and trial field evaluation. Construct. Build. Mater. 2018, 182, 200-209. [CrossRef]

9. Moreno, F.; Sol, M.; Martin, J.; Pérez, M.; Rubio, M.C. The effect of crumb rubber modifier on the resistance of asphalt mixes to plastic deformation. Mater. Des. 2013, 47, 274-280. [CrossRef]

10. Fang, Y.; Zhan, M.; Wang, Y. The status of recycling of waste rubber. Mater. Des. 2001, 22, 123-128. [CrossRef]

11. Sangiorgi, C.; Eskandarsefat, S.; Tataranni, P.; Simone, A.; Vignali, V.; Lantieri, C.; Dondi, G. A complete laboratory assessment of crumb rubber porous asphalt. Construct. Build. Mater. 2017, 132, 500-507. [CrossRef]

12. Shen, J.; Li, B.; Xie, Z. Interaction between crumb rubber modifier (CRM) and asphalt binder in dry process. Construct. Build. Mater. 2017, 149, 202-206. [CrossRef]

13. Hassan, N.A.; Airey, G.D.; Jaya, R.P.; Mashros, N.; Aziz, M.A. A review of crumb rubber modification in dry mixed rubberised asphalt mixtures. J. Teknol. 2017, 70, 127-134.

14. Pszczoła, M.; Jaczewski, M.; Szydłowski, C.; Judycki, J.; Dołżycki, B. Evaluation of Low Temperature Properties of Rubberized Asphalt Mixtures. Procedia Eng. 2017, 172, 897-904. [CrossRef]

15. Chavez, F.; Marcobal, J.; Gallego, J. Laboratory evaluation of the mechanical properties of asphalt mixtures with rubber incorporated by the wet, dry, and semi-wet process. Construct. Build. Mater. 2019, 205, 164-174. [CrossRef]

16. Brown, E.R.; Mallick, R.B.; Haddock, J.E.; Bukowski, J. Performance of Stone Matrix Asphalt (SMA) Mixtures in the United States; NCAT Report No. 97-1; National Center for Asphalt Technology: Auburn, Alabama, 1997.

17. Moghades Nejad, F.; Aflaki, E.; Mohammadi, M.A. Fatigue behavior of SMA and HMA mixtures. Construct. Build. Mater. 2010, 24, 1158-1165. [CrossRef] 
18. Vignali, V.; Mazzotta, F.; Sangiorgi, C.; Simone, A.; Lantieri, C. Incorporation of rubber powder as filler in a new dry-hybrid technology: Rheological and 3D DEM mastic performances evaluation. Materials 2016, 9, 842. [CrossRef] [PubMed]

19. Underwood, B.S.; Kim, Y.R. Effect of volumetric factors on the mechanical behavior of asphalt fine aggregate matrix and the relationship to asphalt mixture properties. Construct. Build. Mater. 2013, 49, 672-681. [CrossRef]

20. Sánchez, D.B.; Grenfell, J.; Airey, G.; Caro, S. Evaluation of the degradation of fine asphalt-aggregate mixtures containing high reclaimed asphalt pavement contents. Road Mater. Pavement Des. 2017, 18,91-107. [CrossRef]

21. Airey, G.D.; Grenfell, J.R.A.; Apeagyei, A.; Subhy, A.; Lo Presti, D. Time dependent viscoelastic rheological response of pure, modified and synthetic bituminous binders. Mech. Time-Dependent Mater. 2016, $20,3$. [CrossRef]

(C) 2020 by the authors. Licensee MDPI, Basel, Switzerland. This article is an open access article distributed under the terms and conditions of the Creative Commons Attribution (CC BY) license (http://creativecommons.org/licenses/by/4.0/). 